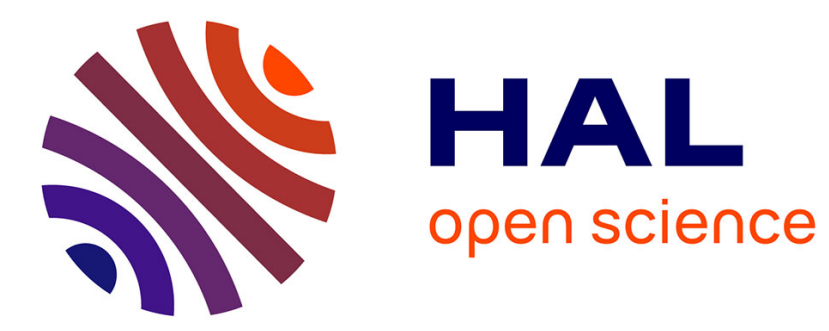

\title{
Conventional Czochralski growth of large Li2MoO4 single crystals
}

\author{
A Ahmine, M Velazquez, V Nagirnyi, I Romet, T Duffar
}

\section{To cite this version:}

A Ahmine, M Velazquez, V Nagirnyi, I Romet, T Duffar. Conventional Czochralski growth of large Li2MoO4 single crystals. Journal of Crystal Growth, 2023. hal-03417415

\section{HAL Id: hal-03417415 \\ https://hal.science/hal-03417415}

Submitted on 5 Nov 2021

HAL is a multi-disciplinary open access archive for the deposit and dissemination of scientific research documents, whether they are published or not. The documents may come from teaching and research institutions in France or abroad, or from public or private research centers.
L'archive ouverte pluridisciplinaire HAL, est destinée au dépôt et à la diffusion de documents scientifiques de niveau recherche, publiés ou non, émanant des établissements d'enseignement et de recherche français ou étrangers, des laboratoires publics ou privés. 


\title{
Conventional Czochralski growth of large $\mathrm{Li}_{2} \mathrm{MoO}_{4}$ single
}

\section{crystals}

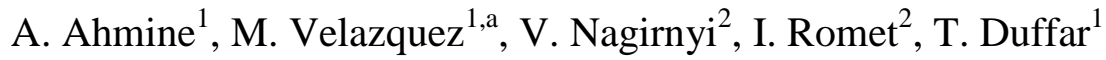 \\ ${ }^{1}$ Univ. Grenoble Alpes, CNRS, Grenoble INP, SIMAP, Grenoble, France \\ ${ }^{2}$ Institute of Physics, University of Tartu, W. Ostwald Str. 1, 50411 Tartu, Estonia \\ ${ }^{a}$ Corresponding Author: matias.velazquez@grenoble-inp.fr
}

\begin{abstract}
Lithium molybdate single crystals up to one kilogram have been grown by a conventional Czochralski process. The growth configuration (geometry, coil, crucible, insulation casing) was optimized by numerical simulation of heat and mass transfer. Dislocations are shown to belong to the basal glide system. Their density $\left(\leq 10^{4} \mathrm{~cm}^{-2}\right)$ and luminescence properties indicate crystal quality similar to that of previously reported crystals grown by Czochralski technique. Numerical simulation of thermo-elastic stresses suggest that the crack observed in one of these crystals is rather due to a mechanical accident than to internal stresses during growth.
\end{abstract}

\section{Keywords}

B1-Lithium molybdate; A2-Czochralski method; A1-Dislocations, luminescence; A1Computer simulation, stresses.

\section{Introduction}


The growth of bulk $\mathrm{Li}_{2} \mathrm{MoO}_{4}$ crystals for the large-scale astroparticle physics experiments that are foreseen by the end of this decade is proceeding apace. The general context of this $R \& D$ effort is related to the quest of the ultimate components of matter, like the neutralino, which is considered as a viable candidate to be the corpuscular component of the dark matter halo of our galaxy $[\mathbf{1 , 2}]$. In the underground dark matter direct detection sites, it would also be useful to characterize the ultimate background noise constituted by fast neutrons which mimics the nuclear recoils possibly induced by Weakly Interacting Massive Particle (WIMP)-nucleus collisions. And more broadly speaking, it would be interesting to develop transportable neutron spectrometers based on heat-scintillation cryogenic bolometers [3]. Another important R\&D effort of these last years is focused on the search for neutrinoless double beta decays $(0 v 2 \beta)$, predicted but never observed, which would prove that neutrinos are their own antiparticles, and so, a new kind of matter, and would also help understanding the origin of their mass $[4,5,6,7]$. In order to detect these extremely rare events, double readout detector modules are built with a core made of a bulk crystal. One or several atomic constituents of these crystals turn out to be an isotope that exhibits the highest capture cross section or emission properties. All the kinetic energy of the neutralino, or of the fast neutron, is collected and recovered as heat and light. In the case of $0 v 2 \beta$ decays, the crystal itself is the source of the decay to be detected exactly in the same way. The crystal is typically several hundred grams heavy, and as the huge mass of the overall detector is to be cooled down to cryogenic temperatures in 20-25 days, it is necessary to develop crystals that have low specific heat and high thermal conductivity, that is, thousands of crystals of high quality. Of course, the scintillation light must be emitted in the spectral range where cheap and 100\%-efficient light detectors exist, typically between $400 \mathrm{~nm}$ and $1.7 \mu \mathrm{m}$. Besides, because of the cost of rare isotopes like ${ }^{100} \mathrm{Mo}$ or ${ }^{6} \mathrm{Li}$, it is necessary to develop purification processes of the initial powders used for the synthesis and recycling processes of the remaining growth loads [8]. The 
purification, recycling and growth processes must be fast enough to comply with the constrained time schedules of these large-scale experiments.

$\mathrm{Li}_{2} \mathrm{MoO}_{4}$ crystals have been grown by the vertical Bridgman technique in a three-zone furnace $[9, \mathbf{1 0}]$, however crystals appeared to be colored, polluted by inclusions and cracked. Barinova et al. [11], proposed a technique of growth from aqueous solution, with strong acoustic mixing in order to destroy the oxide clusters occurring in the liquid [12]; while this technique shows a great potential, only millimetric crystals have been grown so far.

Czochralski technique was used for the growth of the very first single crystals in order to measure their physical properties [13]. This process has been developed, from crystals $34 \mathrm{~g}$ in mass [14] to more than $700 \mathrm{~g}$ [15]. This research effort led to the Low Temperature Gradient Czochralski (LTG-Cz) method, which is now the reference process for the growth of $\mathrm{Li}_{2} \mathrm{MoO}_{4}$ scintillating crystals [15-17]. Rationale for the development of this low gradient technology was the potential vaporization or reduction of the melt constituents in case of too high temperature and crack risks in case of large temperature gradients in the solid [18]. In this technique, the crystal grows inside a totally closed Pt chamber, which prevents volatilization [16] and allows a mass yield of $80 \%$ [8]. This chamber is placed in a three zone furnace and authors claim that crystals are grown under a gradient as low as $1 \mathrm{~K}_{\mathrm{cm}} \mathrm{cm}^{-1}$ [15-18]. However, numerical simulations of heat transfer suggest that it is in fact much larger $[\mathbf{1 9}, \mathbf{2 0}]$. The best bolometric results were obtained with crystals produced in this way [6].

However, this LGT-Cz technique has some drawbacks, first of all the low growth rate $(\leq 0.7$ mm. $\mathrm{h}^{-1}$ ) imposed by the weak temperature gradient [15]. The Pt chamber and crucible are complex in shape and then costly. Because of this chamber, observation of the growing crystal is not possible and growth control remains complex, also due to the three zone furnace [15]. 
Therefore, a more classical Czochralski process, provided that too high temperatures are avoided, could be a less expensive, more productive technique for the growth of high quality $\mathrm{Li}_{2} \mathrm{MoO}_{4}$ crystals. In preceding papers [21, 22], numerical simulation was used for optimizing the hot zone of a Czochralski furnace in order to prevent melt overheating or undercooling, avoid large stresses in the crystal and provide a slightly convex solid-liquid interface (seen from the melt). Based on this approach, the growth of several crystals is described. Characterization is performed in terms of dislocation density and luminescence properties. Special attention is paid to the analysis of the thermal stresses in the growing crystal.

\section{Growth process and crystals}

$\mathrm{Li}_{2} \mathrm{MoO}_{4}$ is synthetized from stoichiometric mixtures of $\mathrm{MoO}_{3}$ (Alfa Aesar 5N5) and $\mathrm{Li}_{2} \mathrm{CO}_{3}$ (Fox-Chemicals, 5N) $\left(\frac{m_{\mathrm{MoO}_{3}}}{m_{\mathrm{LI}_{2} \mathrm{O}_{3}}} \approx 1.948\right)$. Powders are first mixed for 12 hours, then heated at $673 \mathrm{~K}$ in an alumina crucible for another 12 hours. This mixing-heating process is repeated, with heating at $773 \mathrm{~K}$. Then the obtained powder is mixed again and heated at $873 \mathrm{~K}$ for 24 hours, in the Pt crucible (99.99\% purity), which will be used for the growth. The obtained partially sintered powder is molten at $993 \mathrm{~K}$ for 3 hours in order to reduce its volume and provide room for other powder charges. The entire process is repeated until the Pt crucible (80 $\mathrm{mm}$ diameter and $100 \mathrm{~mm}$ in height, for a crystal diameter of $50 \mathrm{~mm}$ ) is full. This heating process, with several steps, is preferred in order to avoid vaporization of $\mathrm{MoO}_{3}$ at high temperature. Table 1 gives the qualitative chemical evolution of the powder all along the process, measured from X-ray diffraction (XRD) diagrams.

\begin{tabular}{|l|l|l|}
\hline After heating at $673 \mathrm{~K}$ & After heating at $773 \mathrm{~K}$ & $\begin{array}{l}\text { After heating at } 873 \mathrm{~K} \text { (before } \\
\text { melting) }\end{array}$ \\
\hline $\mathrm{Li}_{2} \mathrm{MoO}_{4}$ (Large amount) & $\mathrm{Li}_{2} \mathrm{MoO}_{4}$ (Large amount) & $\mathrm{Li}_{2} \mathrm{MoO}_{4}$ \\
\hline
\end{tabular}




\begin{tabular}{|l|l|l|}
\hline $\mathrm{Li}_{4} \mathrm{Mo}_{5} \mathrm{O}_{17}$ (Small amount) & $\mathrm{Li}_{4} \mathrm{Mo}_{5} \mathrm{O}_{17}$ (Small amount) & \\
$\mathrm{MoO}_{3}$ (Large amount) & $\mathrm{MoO}_{3}$ (Very few) & \\
$\mathrm{Li}_{2} \mathrm{CO}_{3}$ (Large amount) & & \\
\hline
\end{tabular}

Table 1 XRD qualitative analysis of the chemical composition of the $\left(\mathrm{MoO}_{3}+\mathrm{Li}_{2} \mathrm{CO}_{3}\right)$ powder mixture along the heating steps.

The crucible is then placed in the center of an open air vessel, with the various heating and screening elements as defined through the numerical simulation optimization [21]. Figure 1left shows this heating configuration. It is based on the induction heating of a susceptor element (Kanthal®), which provides much more flexibility than direct coupling to the Pt crucible. The alumina pulling shaft and Pt seed holder are introduced through the top opening, with special care for concentricity of the whole system. A viewing port, also used for pyrometric temperature measurements, exists on the top plate (not shown). The external jacket is continuously cooled with water at a controlled temperature of $28^{\circ} \mathrm{C}$. All growth parameters are controlled by automation software (Cyberstar®) through continuous measurement of the crystal weight and adjustment of the induction coil power. Therefore, the sequence of shoulder-cylinder-tail growth phases is programmed in terms of pulling rate, rotation rate and diameter increase-decrease versus time, from the very beginning of the pulling. 

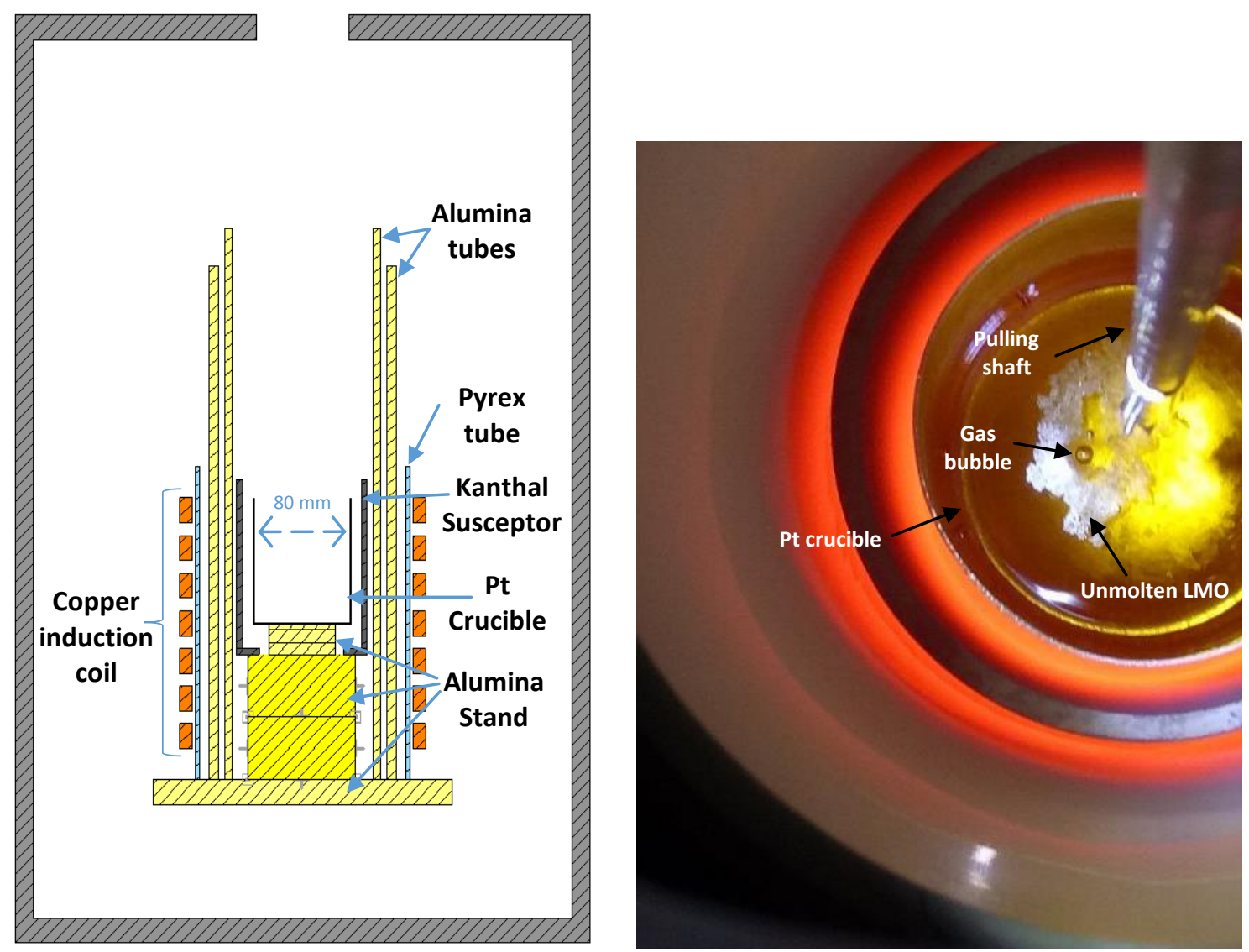

Figure1 Left: Heating and screening elements inside the open air set-up. Right: view from the top of the equipment, during the melting phase.

The material is slowly melted (Figure 1-Right) and soaked for 24 hours at $1003 \mathrm{~K}$, as measured by the pyrometer on the liquid surface. Seeds oriented [11̄20] and [0001] were used, without significant effect on the growth progress. After careful seeding, growth is usually begun while the measured weight is slightly decreasing, in order to get a seed necking. Then the fully programmed pulling is started. The rotation rate was always $5 \mathrm{rpm}$ and pulling rate $2 \mathrm{~mm} \cdot \mathrm{h}^{-1}$. While the extraction process can also be performed by the pulling software, it was usually performed manually (at $30 \mathrm{~mm} \cdot \mathrm{h}^{-1}$ ) in order to avoid a too strong thermal shock to the crystal. The furnace is then slowly cooled down. It should be noted that absolutely no deposit of any kind has been found in the chamber after growth.

Three crystals with a diameter of $50 \mathrm{~mm}$ (Figure 2) have been grown under the conditions presented above. Masses scaled from $532 \mathrm{~g}$ to $967 \mathrm{~g}$ and material yield from $66 \%$ to $81.4 \%$. 
Two other crystals, with a diameter $40 \mathrm{~mm}$, were grown from 3N LMO powder (SigmaAldrich) in a slightly modified configuration. However, they presented a yellowish color and some inclusions (cf. Figure 5).
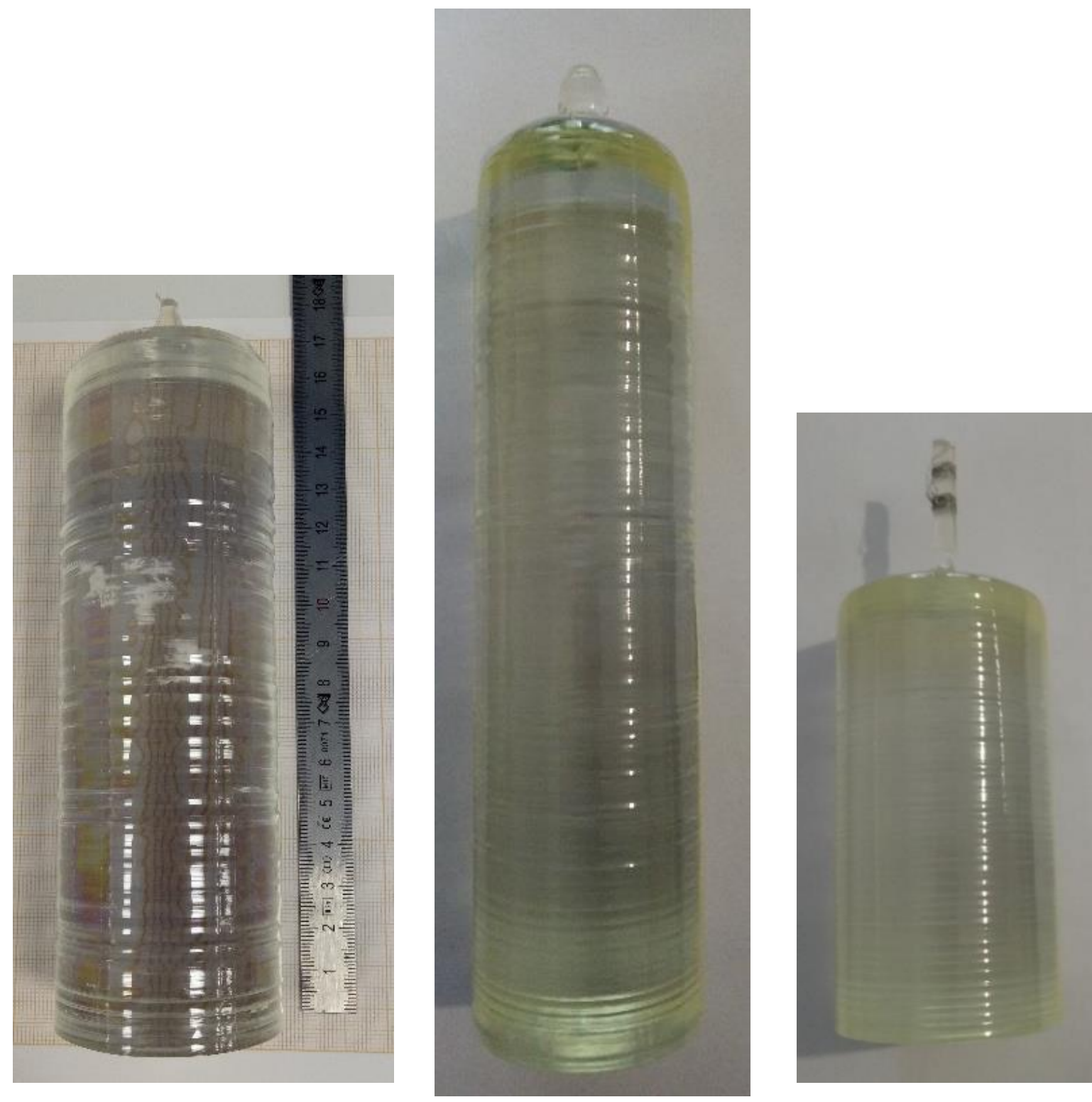

Figure $2 \mathrm{Li}_{2} \mathrm{MoO}_{4}$ crystals, $50 \mathrm{~mm}$ in diameter and, respectively, $820 \mathrm{~g}, 967 \mathrm{~g}$, and $532 \mathrm{~g}$ in mass, pulled with the optimized Czochralski configuration.

\section{Characterization}

X-ray diffraction analyses only show rhombohedral $(R \overline{3}) \mathrm{Li}_{2} \mathrm{MoO}_{4}$ peaks. Several Laue back reflection diagrams, taken on various places on the ingots, have shown that they are single 
crystals without twin or grain. As the material is hygroscopic, cutting and polishing are performed under ethanol instead of water.

\section{3-1 Dislocations}

Etch pit densities have been measured on polished (roughness $0.15 \mu \mathrm{m}$ ) and acetone-cleaned surfaces randomly cut inside the crystals. Water, chosen with consideration to the crystal hygroscopicity, appeared to be an excellent etchant. Typical etching times, at ambient temperature, range from $20 \mathrm{~s}$ to $40 \mathrm{~s}$, depending on the surface orientation. Dislocation densities were automatically measured on the microscopic photographs, using the "particle analysis" ImageJ® routine. This numeric procedure has been validated by comparison with one-by-one pit counting. Figure 3 shows the counting procedure applied to a [11 $\overline{2} 0]$ surface, etched 20 seconds, on which pits appear as small diamonds elongated along the $c$ direction. The dislocation density is taken as the mean value of the etch-pit densities of all the areas analyzed on the surface. The results are in the range $[0.8-1.4] 10^{4} \mathrm{~cm}^{-2}$ for the crystals 50 $\mathrm{mm}$ in diameter. The less pure crystals $40 \mathrm{~mm}$ in diameter are in the range $[1.7-2.8] 10^{4} \mathrm{~cm}^{-2}$ with numerous dislocations appearing around precipitates occurring in the material. Energy dispersive shows that these precipitates contain $\mathrm{Si}, \mathrm{P}$ and $\mathrm{V}$, possibly coming from the $3 \mathrm{~N}$ raw material and the old, smaller, Pt crucible used for these crystals. 


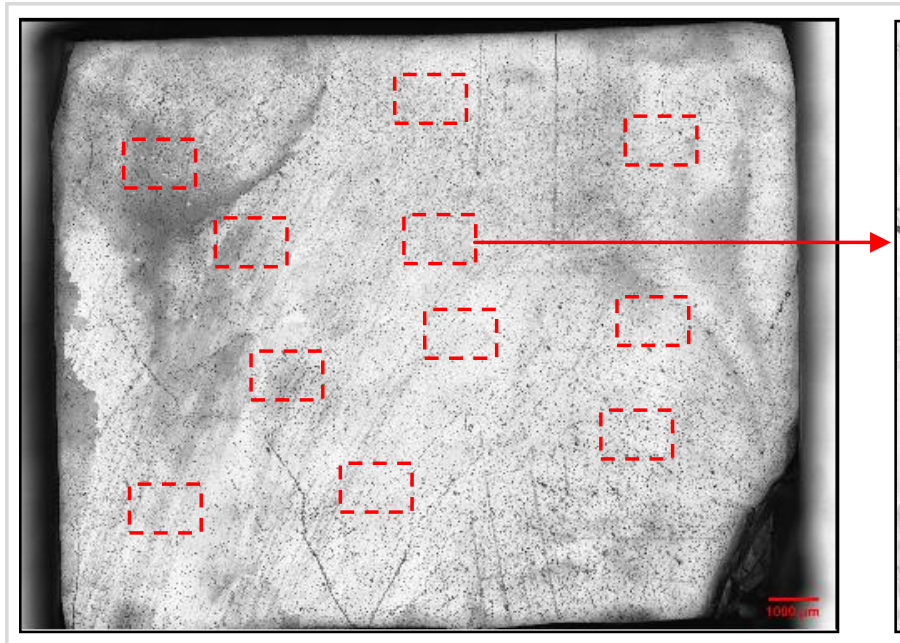

a)

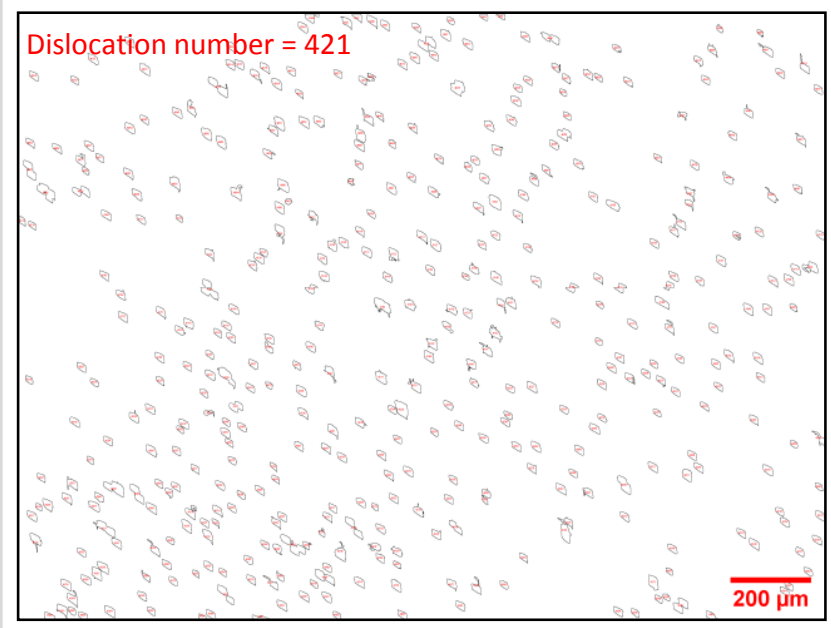

d)

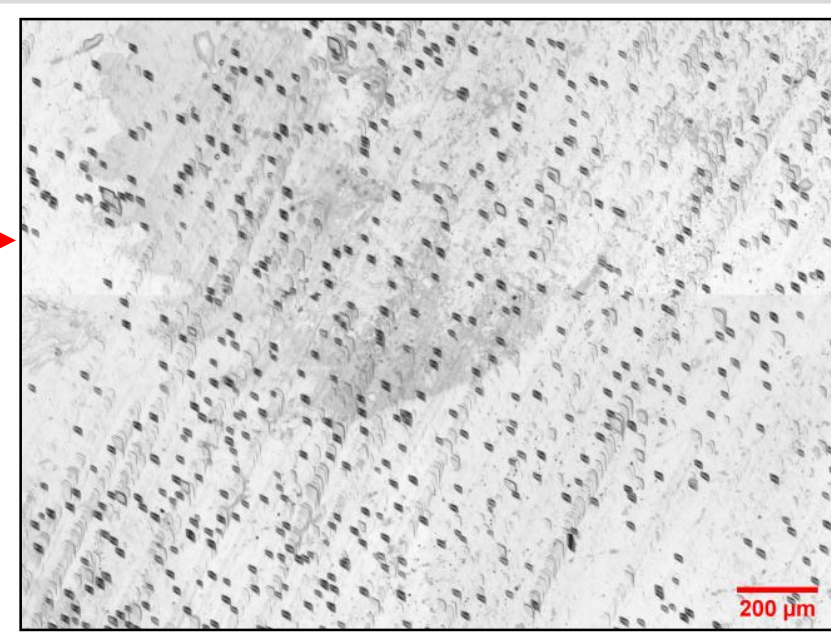

b)

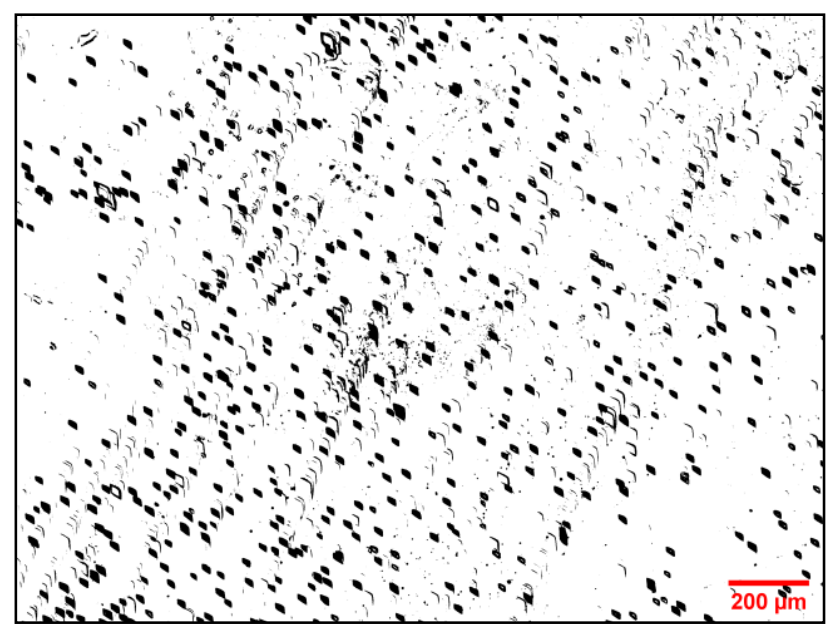

c)

Figure 3 Etch-pit density measurement with ImageJ software. a) Full sample [11̄̄0] surface; b) one of the analyzed areas; c) binary (B\&W) image; d) etch-pit numbering.

Figure 4 shows the etched (0001) and (112̄0) faces of a cube cut inside a crystal. The (1120) surface, etched for $20 \mathrm{~s}$, shows well defined etch-pits, while the (0001) surface shows only polishing defects and no pits in spite of a $40 \mathrm{~s}$ etching time. This result suggests that dislocations in $\mathrm{Li}_{2} \mathrm{MoO}_{4}$ are oriented along the [11 20 ] direction and contained in the (0001) plane, corresponding to the basal glide system. This is the most common slip system in rhombohedral crystals [23, 24]. 


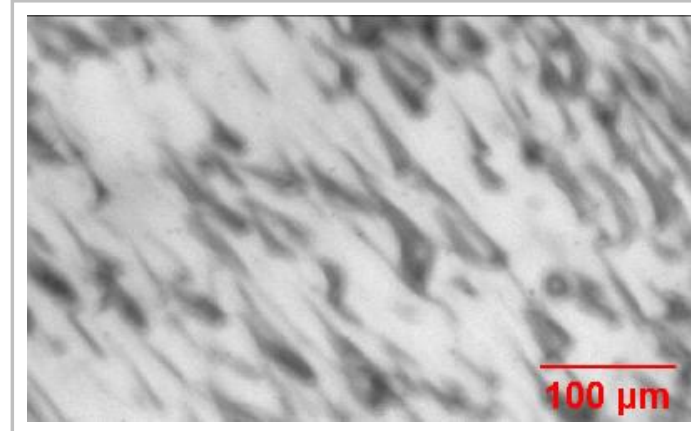

a)

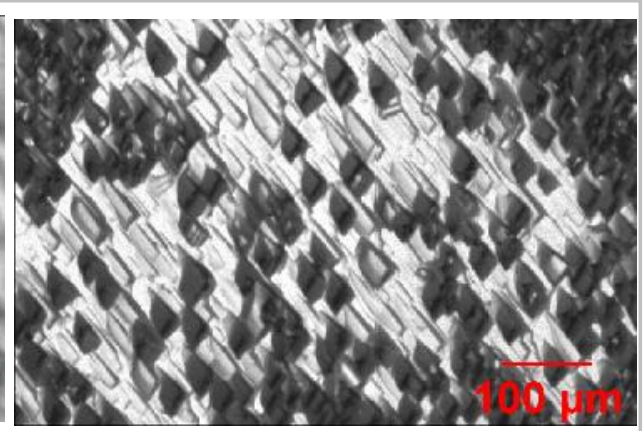

b)

Figure 4 Photos of two etched faces of a $\mathrm{Li}_{2} \mathrm{MoO}_{4}$ cube. a) [0001] face, b) [1120] face.

\section{3-2 Luminescence properties}

Luminescence features of the grown crystals have been studied by the techniques described in [25]. They are similar to those in $\mathrm{Li}_{2} \mathrm{MoO}_{4}$ crystals grown by the conventional Czochralski and Low-Temperature-Gradient Czochralski methods [26]. The emission spectrum at $4.2 \mathrm{~K}$ is represented by a non-elementary band in the region of 1.5-3 eV (Figure 5). The peak position of the emission band varies from 2.1 to $2.2 \mathrm{eV}$ depending on the exciting photon energy (compare curves 1 and 2). The high-energy component of the emission is excited more efficiently in the band near $4.4 \mathrm{eV}$, while the low-energy part is more intense under excitation deeper in the fundamental absorption region (curves 3 and 4). According to the time-resolved spectroscopy studies, the emission spectrum of $\mathrm{Li}_{2} \mathrm{MoO}_{4}$ crystals comprises two strongly overlapping bands peaking at 2.08 and $2.25 \mathrm{eV}$, which are attributed, respectively, to the radiative decay of self-trapped excitons (STEs) and excitons stabilized by crystal structure defects, probably oxygen vacancies [26]. The ratio of their intensities depends on the excitation energy and number of structural defects in the sample. The decay times of the STE and defect-related emissions are substantially different at $4.2 \mathrm{~K}$ (130 and $35 \mu \mathrm{s}$, respectively), which allows reliable distinguishing of the corresponding emissions in time-resolved spectroscopy experiments. The ratio of the integrated intensity of the STE emission to that of the defect related emission, both calculated from a decay curve recorded at excitation $4.75 \mathrm{eV}$, 
was suggested in [26] as a measure of the relative number of defect-related centers in a crystal. Its value was equal to 4.7 in the best $\mathrm{Li}_{2} \mathrm{MoO}_{4}$ crystals grown by Low-TemperatureGradient Czochralski technique and 2.7 in the case of growth by the conventional Czochralski method studied in [26]. The decay curve recorded for a present crystal at $4.2 \mathrm{~K}$ is shown in the inset of Figure 5. It can be reliably decomposed into two decay components with decay times $\tau_{1}=130$ and $\tau_{2}=35 \mu \mathrm{s}$, whereas the ratio of their intensities $\mathrm{S}_{1} / \mathrm{S}_{2}=2.3$ is close to 2.7. This shows clearly that large-size single crystals grown here by an optimized Czochralski technique possess a relative number of lattice defects and structural quality similar to those of the crystals grown by the conventional Czochralski method.

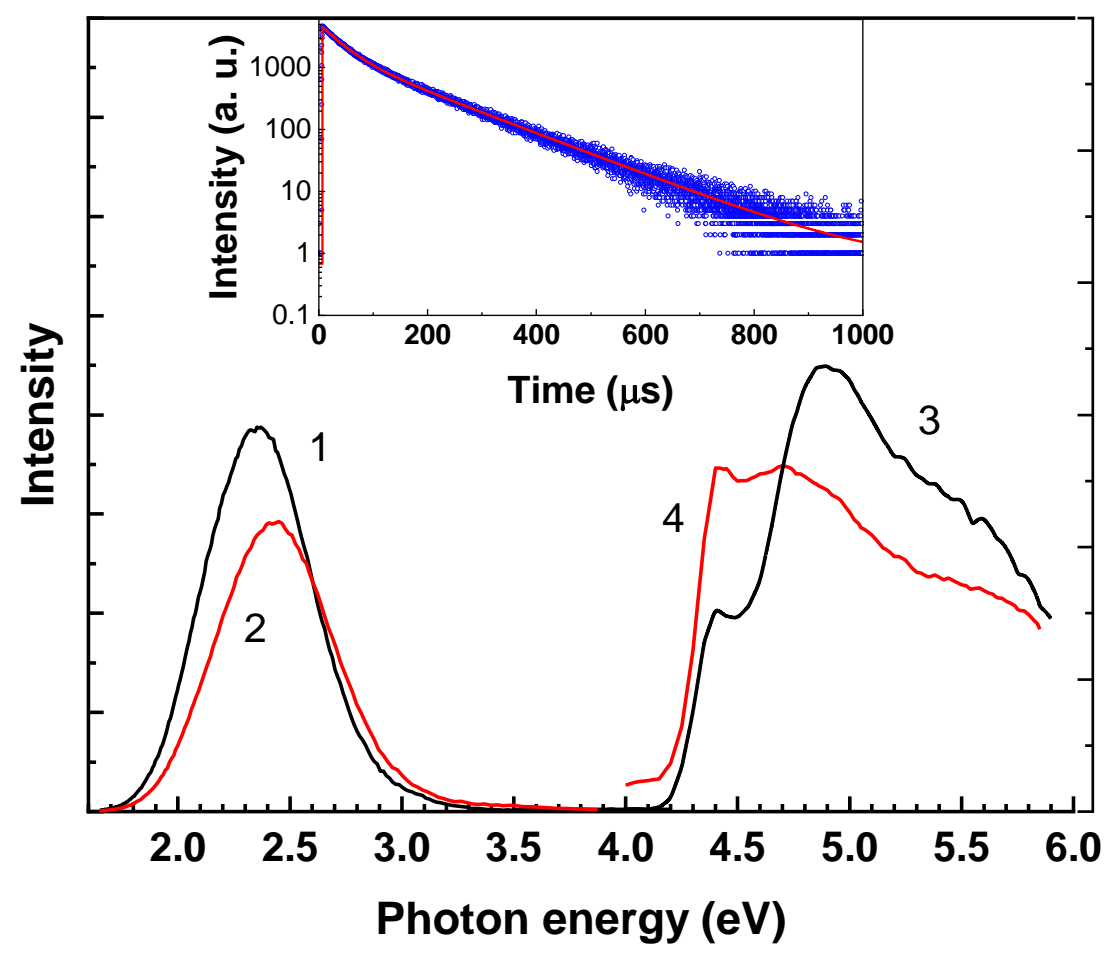

Figure 5 Emission spectra of a $\mathrm{Li}_{2} \mathrm{MoO}_{4}$ crystal measured at excitation energies 4.8 (1) and $4.6 \mathrm{eV}$ (2) and excitation spectra for $2.7 \mathrm{eV} \mathrm{(3)} \mathrm{and} 1.95 \mathrm{eV}$ (4) emissions. Inset: the decay curve measured at excitation energy $4.75 \mathrm{eV}$ (blue circles) and fitting of the experimental curve with two decay components of 35 and $130 \mu$ s (red solid line).

\section{Stresses in the growing crystal}


Metal molybdates are known as fragile materials where cracks are expected to occur during growth [18]. As depicted in figure 6 , one of the $40 \mathrm{~mm}$ diameter crystal, grown from $3 \mathrm{~N}$ commercial molybdate, has shown a transverse crack at the end of growth. The crack plane was characterized as (0001) by Laue pattern analysis, which is the weakest plane in such crystals. The specific orientation is due to seed at $15^{\circ}$ from $<11 \overline{2} 0>$.

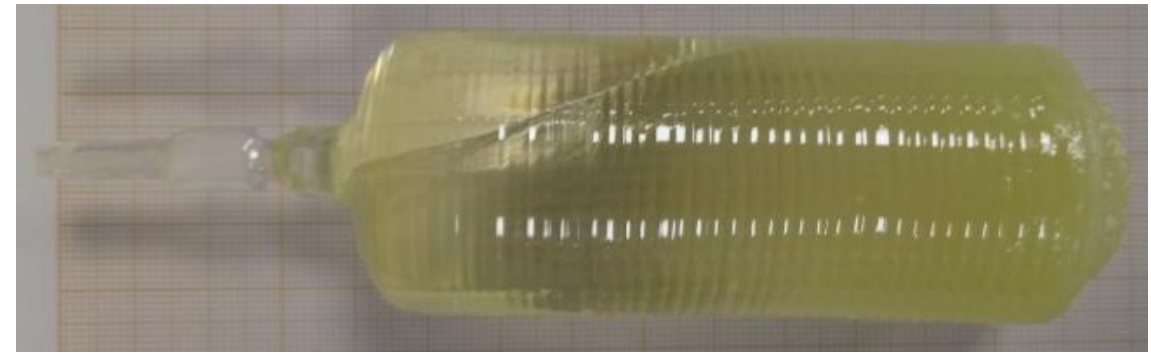

Figure $6 \mathrm{Li}_{2} \mathrm{MoO}_{4}$ crystal, $40 \mathrm{~mm}$ in diameter, and $366 \mathrm{~g}$ in mass, showing crack during growth process.

In order to understand the origin of this crack better, stresses occurring during growth have been calculated by finite element numerical simulation of heat transfer and thermo-elasticity, by the Comsol @ software. The modelling procedure is the same as presented in [21, 22], applied to the specific set-up configuration used for growing this crystal. Several pseudostationary calculations (i.e. taking into account pulling rate and latent heat release) have been performed. Figure 7 shows the temperature field at three times during the growth. The 
interface deflection is small, $<4 \mathrm{~mm}$. The temperature gradient in the solid reaches a maximum of $50 \mathrm{~K} . \mathrm{cm}^{-1}$, and is always situated close to the triple phase line.

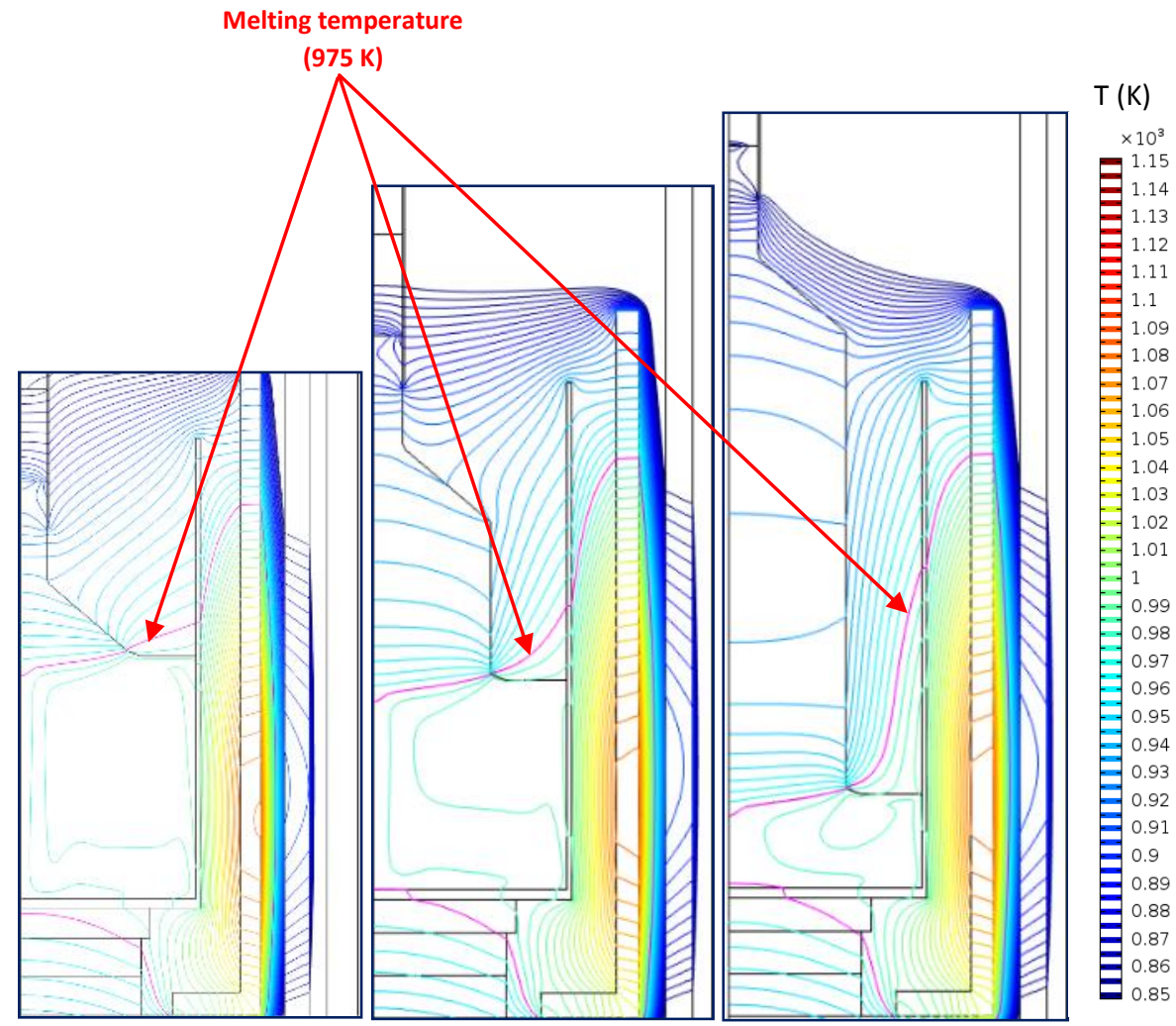

a)

b)

c)

Figure 7 Temperature field in the crystal and surroundings at three times during growth: a) end of shoulder, b) $3 \mathrm{~cm}$ of cylinder, c) end of growth.

Thermo-elastic stress calculations are based on the computed axi-symmetric temperature field and take into account anisotropic dilatation coefficient [27] and elastic constants [28]. Figure 8 shows the distribution of tensile stresses projected on the crack plane observed on figure 6 . 


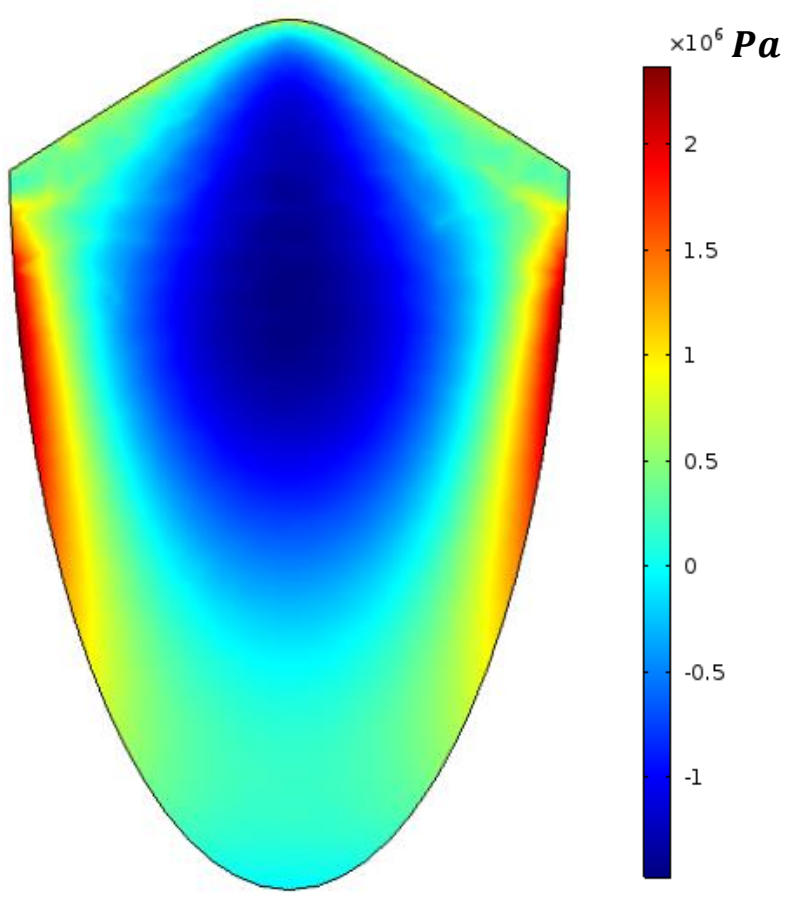

Figure 8 Compressive and tensile stresses during growth, projected on the fracture plane of the crystal shown on figure 6.

It can be seen that the maximal tensile stress is $2 \mathrm{MPa}$, below the fracture stress measured at high temperature as $3 \mathrm{MPa}$ [28]. This maximum is located on the cylinder side, far from the upper or lower ends of the crack, where it was likely to begin. This result suggests that the crack was rather due to some unexpected vibration or shock occurring during the growth and that its expansion was helped by the precipitates observed in the crystal.

\section{Conclusion}

After the optimization of the synthesis process, three $\mathrm{Li}_{2} \mathrm{MoO}_{4}$ crystals, $50 \mathrm{~mm}$ in diameter and up to $1 \mathrm{~kg}$ in mass, have been successfully grown by a conventional Czochralski process, at a velocity of $2 \mathrm{~mm} \cdot \mathrm{h}^{-1}$ and a mass yield larger than $80 \%$. It should be noted that these parameters have not been optimized during this study: in view of the fluency with which the crystals have been pulled, they can certainly be increased. No chemical deposit has been 
observed in the setup after growth, so that material evaporation, if any, can be considered as negligible.

This growth ease and reproducibility is certainly due to the combination of a careful optimization of the furnace design, by numerical simulation, and the efficiency of the Cyberstar® control software. By the way, the crystals shown on figure 3 have been produced after only ten experiments, including mechanical and power adjustment. This demonstrates the usefulness of numerical simulation optimization, in terms of time, manpower and money saving.

Dislocation densities are less than $10^{4} \mathrm{~cm}^{-2}$ for the best crystals and the luminescence properties are similar to those of previously reported smaller crystals grown by a conventional Czochralski process.

One smaller crystal, grown from less pure raw material and having inclusions, has shown a crack after growth. Computation of thermo-elastic stresses during this growth show that the crack was likely due to unexpected shock occurring during the growth, rather than to too high thermo-elastic tensile stresses.

All in all it appears that the numerically optimized conventional Czochralski pulling is an efficient process for the mass production of $\mathrm{Li}_{2} \mathrm{MoO}_{4}$ single crystals. One bolometer has been built from one crystal and is now under evaluation at the Canfranc underground laboratory.

\section{Acknowledgments}

This research has been financially supported by the ANR-Clymène project, ref. ANR-16CE08-0018-02. The support of the Estonian Research Council (project PUT PRG111) and ERDF funding in Estonia granted to the Centre of Excellence TK141 “Advanced materials and high-technology devices for sustainable energetics, sensorics and nanoelectronics (HiTechDevices)" (grant no. 2014-2020.4.01.15-0011) is also gratefully acknowledged. 
Growths were performed with a Cyberstar pulling system and control software, provided by the Cristalinnov technical platform (Sainte Hélène du Lac 73800, France). Laue diffraction experiments were performed with the help of H. Roussel, from the Grenoble-INP CMTC characterization platform.

\section{Bibliography}

[1] G. Angloher, E. Armengaud, C. Augier, A. Benoit, T. Bergmann, J. Blümer, A. Broniatowski, V. Brudanin, Ph. Camus, M. Chapellier, N. Coron, G. A. Cox, C. Cuesta, F. A. Danevich, L. Dumoulin, K. Eitel, A. Erb, A. Ertl, F. v. Feilitzsch, D. Filosofov, E. García, J. Gascon, G. Gerbier, C. Ginestra, J. Gironnet, A. Giuliani, M. Gros, A. Gütlein, D. Hauff, S. Henry, G. Heuermann, J. Jochum, S. Jokisch, A. Juillard, C. Kister, M. Kleifges, H. Kluck, V. Y. Kozlov, H. Kraus, V. A. Kudryavtsev, J.-C. Lanfranchi, P. Loaiza, J. Loebell, I. Machulin, S. Marnieros, M. Martínez, A. Menshikov, A. Münster, X.-F. Navick, C. Nones, Y. Ortigoza, P. Pari, F. Petricca, W. Potzel, P. P. Povinec, F. Pröbst, J. Puimedón, F. Reindl, M. Robinson, T. Rolón, S. Roth, K. Rottler, S. Rozov, Ch. Sailer, A. Salinas, V. Sanglard, M. L. Sarsa, K. Schäffner, B. Schmidt, S. Scholl, S. Schönert, W. Seidel, B. Siebenborn, M. v. Sivers, Ch. Strandhagen, R. Strauss, A. Tanzke, V. I. Tretyak, M. Turad, A. Ulrich, I. Usherov, Ph. Veber, M. Velázquez, J. A. Villar, O. Viraphong, R. J. Walker, S. Wawoczny, M. Weber, M. Willers, M. Wüstrich, E. Yakushev, X. Zhang, A. Zöller, 2014. EURECA Conceptual Design Report, Physics of the Dark Universe, 3, 41-74.

[2] A. H. Abdelhameed, G. Angloher, P. Bauer, A. Bento, E. Bertoldo, C. Bucci, L. Canonica, A. D'Addabbo, X. Defay, S. Di Lorenzo, A. Erb, F. v. Feilitzsch, N. Ferreiro Iachellini, S. Fichtinger, A. Fuss, P. Gorla, D. Hauff, J. Jochum, A. Kinast, H. Kluck, H. Kraus, A. Langenkämper, M. Mancuso, V. Mokina, E. Mondragon, A. Münster, M. Olmi, T. Ortmann, C. Pagliarone, L. Pattavina, F. Petricca, W. Potzel, F. Pröbst, F. Reindl, J. Rothe, K. Schäffner, J. Schieck, V. Schipperges, D. Schmiedmayer, S. Schönert, C. Schwertner, M. Stahlberg, L. Stodolsky, C. Strandhagen, R. Strauss, C. Türkoğlu, I. Usherov, M. Willers, V. Zema, M. Chapellier, A. Giuliani, C. Nones, D. V. Poda, V. N. Shlegel, M. Velázquez, A. S. Zolotarova, 2019. First results on sub-GeV spin-dependent dark matter with ${ }^{7}$ Li, Eur. Phys. J. C, 79 (7), 630/1-7. 
[3] M. Martínez, N. Coron, C. Ginestra, J. Gironnet, V. Gressier, J. Leblanc, P. de Marcillac, T. Redon, P. di Stefano, L. Torres, P. Veber, M. Velázquez, O. Viraphong, 2012. Scintillating bolometers for fast neutron spectroscopy in rare events searches, Proceedings of the $12^{\text {th }}$ International Conference on Topics in Astroparticle and Underground Physics (TAUP, Munich, september 2011), J. Phys.: Conf. Series, 375 (2012) 012025, 1-4.

[4] T.B. Bekker, N. Coron, F.A. Danevich, V.Ya. Degoda, A. Giuliani, V.D. Grigorieva, N.V. Ivannikova, M. Mancuso, P. de Marcillac, I.M. Moroz, C. Nones, E. Olivieri, G. Pessina, D. V. Poda, V.N. Shlegel, V.I. Tretyak, M. Velazquez, 2016. Aboveground test of an advanced $\mathrm{Li}_{2} \mathrm{MoO}_{4}$ scintillating bolometer to search for neutrinoless double beta decay of ${ }^{100} \mathrm{Mo}$, Astroparticle Physics, 72, 38-45.

[5] G. Buşe, A. Giuliani, P. de Marcillac, S. Marnieros, C. Nones, V. Novati, E. Olivieri, D.V. Poda, T. Redon, J.-B. Sand, P. Veber, M. Velázquez, A.S. Zolotarova, 2018. First scintillating bolometer tests of a CLYMENE R\&D on $\mathrm{Li}_{2} \mathrm{MoO}_{4}$ scintillators towards a largescale double-beta decay experiment, Nucl. Instrum. Meth. Phys. Res. A, 891, 87-91.

[6] E. Armengaud, C. Augier, A. S. Barabash, F. Bellini, G. Benato, A. Benoît, M. Beretta, L. Bergé, J. Billard, Yu. A. Borovlev, Ch. Bourgeois, M. Briere, V. Brudanin, P. Camus, L. Cardani, N. Casali, A. Cazes, M. Chapellier, F. Charlieux, M. de Combarieu, I. Dafinei, F. A. Danevich, M. De Jesus, L. Dumoulin, K. Eitel, E. Elkhoury, F. Ferri, B. K. Fujikawa, J. Gascon, L. Gironi, A. Giuliani, V. D. Grigorieva, M. Gros, E. Guerard, D. L. Helis, H. Z. Huang, R. Huang, J. Johnston, A. Juillard, H. Khalife, M. Kleifges, V. V. Kobychev, Yu. G. Kolomensky, S. I. Konovalov, A. Leder, J. Kotila, P. Loaiza, L.Ma, E. P. Makarov, P. de Marcillac, L. Marini, S. Marnieros, D. Misiak, X.-F. Navick, C. Nones, V. Novati, E. Olivieri, J. L. Ouellet, L. Pagnanini, P. Pari, L. Pattavina, B. Paul, M. Pavan, H. Peng, G. Pessina, S. Pirro, D. V. Poda, O. G. Polischuk, E. Previtali, Th. Redon, S. Rozov, C. Rusconi, V. Sanglard, K. Schäffner, B. Schmidt, Y. Shen, V. N. Shlegel, B. Siebenborn, V. Singh, C. Tomei, V. I. Tretyak, V. I. Umatov, L. Vagneron, M. Velázquez, M. Weber, B. Welliver, L. Winslow, M. Xue, E. Yakushev, A. S. Zolotarova, 2020. Precise measurement of $2 v \beta \beta$ decay of ${ }^{100}$ Mo with the CUPID-Mo detection technology, Eur. Phys. J. C, 80 (7), 674/1-10.

[7] E. Armengaud, C. Augier, A. S. Barabash, F. Bellini, G. Benato, A. Benoît, M. Beretta, L. Bergé, J. Billard, Yu. A. Borovlev, Ch. Bourgeois, V. B. Brudanin, P. Camus, L. Cardani, N. Casali, A. Cazes, M. Chapellier, F. Charlieux, D. Chiesa, M. de Combarieu, I. Dafinei, F. A. Danevich, M. De Jesus, T. Dixon, L. Dumoulin, K. Eitel, F. Ferri, B. K. Fujikawa, J. Gascon, L. Gironi, A. Giuliani, V. D. Grigorieva, M. Gros, E. Guerard, D. L. Helis, H. Z. Huang, R. Huang, J. Johnston, A. Juillard, H. Khalife, M. Kleifges, V. V. Kobychev, Yu. G. 
Kolomensky, S.I. Konovalov, A. Leder, P. Loaiza, L. Ma, E. P. Makarov, P. de Marcillac, R. Mariam, L. Marini, S. Marnieros, D. Misiak, X.-F. Navick, C. Nones, E. B. Norman, V. Novati, E. Olivieri, J. L. Ouellet, L. Pagnanini, P. Pari, L. Pattavina, B. Paul, M. Pavan, H. Peng, G. Pessina, S. Pirro, D. V. Poda, O. G. Polischuk, S. Pozzi, E. Previtali, Th. Redon, A. Rojas, S. Rozov, C. Rusconi, V. Sanglard, J. A. Scarpaci, K. Schäffner, B. Schmidt, Y. Shen, V. N. Shlegel, B. Siebenborn, V. Singh, C. Tomei, V. I. Tretyak, V. I. Umatov, L. Vagneron, M. Velázquez, B. Welliver, L. Winslow, M. Xue, E. Yakushev, M. Zarytskyy, A. S. Zolotarova, 2021. A new limit for neutrinoless double-beta decay of ${ }^{100}$ Mo from the CUPIDMo experiment, Phys. Rev. Lett., 126 (18), 181802.

[8] V. N. Shlegel, L. Berge, R. S. Boiko, M. Chapellier, D. M. Chernyak, N. Coron, F. A. Danevich, R. Decourt, V. Ya. Degoda, L. Devoyon, A. Drillien, L. Dumoulin, C. Enss, A. Fleischmann, L. Gastaldo, A. Giuliani, M. Gros, S. Herve, I. M. Ivanov, V. V. Kobychev, Ya. P. Kogut, F. Koskas, M. Loidl, P. Magnier, E. P. Makarov, M. Mancuso, P. de Marcillac, S. Marnieros, C. Marrache-Kikuchi, S. G. Nasonov, X. F. Navick, C. Nones, E. Olivieri, B. Paul, Y. Penichot, G. Pessina, O. Plantevin, D. V. Poda, T. Redon, M. Rodrigues, O. Strazzer, M. Tenconi, L. Torres, V. I. Tretyak, Ya. V. Vasiliev, M. Velazquez, O. Viraphong, V. N. Zhdankov, (2014) Purification of molybdenum oxide, growth and characterization of medium size zinc molybdate crystals for the LUMINEU program. Proceedings of the 3rd RPScint "Radiopure scintillators" workshop, European Physical Journal Web of Conferences, 65, 03001, p.1-6.

[9] P. Chen, L. Jiang, Y. Chen, H. Chen, M. Xue, Y. Zhang, Z. Xu, 2018. Bridgman growth and luminescence properties of $\mathrm{Li}_{2} \mathrm{MoO}_{4}$ single crystal. Materials Letters. 215, 225-228.

[10] P. Chen, R. Wei, L. Jiang, S. Yang, Y. Chen, Z. Wang, H. Yu, H. Chen, 2018. Crystal defects of $\mathrm{Li}_{2} \mathrm{MoO}_{4}$ scintillators grown by Bridgman method. J. Crystal Growth. 500, 80-84.

[11] O.P. Barinova, I.M. Ermochenkov, Z.S. Kuchuk, S.K. Kirsanova, S.D. Belov, A.P. Sadovskii, E.N. Mozhevitina, A.V. Khomyakov, I. K. Avetissov, 2015 (2016 for Eng. Trad.). Growth of $\mathrm{Li}_{2} \mathrm{MoO}_{4}$ crystals from activated water solutions. Glass and Ceramics. 72, 11-12.

[12] R.Yamdagni, C. Pupp, R.F. Porter, 1970. Mass spectrometric study of the evaporation of lithium and sodium molybdates and tungstates. J. Inorg, Nucl. Chem. 32, 3509-3523.

[13] I. D. Tretyak, B.F. Bilien'kii, M.V. Markiv, P.V. Pansyuk, 1974. Growth, symmetry, lattice parameters, and optical properties of lithium molybdate single crystals. Kristallografiya. 19, 876-877. 
[14] O. P. Barinova, F. Capelal, R. Cerulli, F.A. Danevich, S.V. Kirsanova, V.V. Kobychev, M. Laubenstein, S.S. Nagorny, F. Nozzoli, V.I. Tretyak, 2009. Intrinsic radiopurity of a $\mathrm{Li}_{2} \mathrm{MoO}_{4}$ crystal. Nuclear Instruments and Methods in Physics Research A, 607, 573-575.

[15] V. Grigorieva, V. Shlegel, T. Bekker, N. Ivannikova, A. Giuliani, P. de Marcillac, S. Marnieros, V. Novati, E. Olivieri, D. Poda, C. Nones, A. Zolotarova, F. Danevich, 2017. $\mathrm{Li}_{2} \mathrm{MoO}_{4}$ crystals grown by the low-thermal-gradient Czchoralski technique. J.Materials Science and Engineering. B 7, 63-70.

[16] V. Grigorieva, V. Shlegel, Y. Borovlev, A. Ryadun, T.B. Bekker, 2019. Bolometric molybdate crystals grown by low-thermal-gradient Czochralski technique. J. Crystal Growth. $523,125144$.

[17] V.N. Shlegel, Y. Borolev, D.N. Grigoriev, V.D. Grigorieva, F.A. Danevich, N.V. Ivannikova, A.G. Postupaeva, Y.V. Vasiliev, 2017. Recent progress in oxide scintillation crystals development by low-thermal gradient Czochralski technique for particle physics experiments. Int. Conf. Instrumentation for Colliding Beam Physics. Novosibirsk, Russia, $27^{\text {th }}$ February $-3^{\text {rd }}$ March 2017. J. Instrumentation, 12, C08011.

[18] E.N. Galashov, T.M. Denisova, I.M. Ivanov, E.P. Makarov, V.N. Mamontov, V.N. Schlegel, Y.G. Stenin, Y.V. Vasiliev, V.N. Zhdankov, 2010. Growing of ${ }^{106} \mathrm{CdWO}_{4}, \mathrm{ZnWO}_{4}$, and $\mathrm{ZnMoO}_{4}$ scintillation crystals for rare events search by low thermal gradient Czochralski technique. Functional Materials, 17, No. 4, 504.

[19] I.Y. Evstratov, S. Rukolaine, V.S. Yuferev, M.G. Vasiliev, A.B. Fogelson, V.M. Mamedov, V.N. Shlegel, Y.V. Vasiliev, Y.N. Makarov, 2002. Global analysis of heat transfer in growing $\mathrm{BGO}$ crystals $\left(\mathrm{Bi}_{4} \mathrm{Ge}_{3} \mathrm{O}_{12}\right)$ by low-gradient Czochralski method. J. Crystal Growth. 235, 371-376.

[20] O.N. Budenkova, M.G. Vasiliev, V.N. Shlegel, N.V. Ivannikova, R.I. Bragin, V.N. Kalaev, 2005. Comparative analysis of the heat transfer processes during growth of $\mathrm{Bi}_{12} \mathrm{GeO}_{20}$ and $\mathrm{Bi}_{4} \mathrm{Ge}_{3} \mathrm{O}_{12}$ crystals by the low-thermal-gradient Czochralski technique Crystallography reports. 50, S100-S105.

[21] C. Stelian, M. Velázquez, P. Veber, A. Ahmine, J.-B. Sand, G. Buşe, H. Cabane, T. Duffar, 2018. Numerical modeling of Czochralski growth of $\mathrm{Li}_{2} \mathrm{MoO}_{4}$ crystals for heatscintillation cryogenic bolometers. J.Crystal Growth, 492, 6-12.

[22] C. Stelian, M. Velazquez, P. Veber, A. Ahmine, T. Duffar, P. de Marcillac, A. Giuliani, D.V. Poda, S. Marnieros, C. Nones, V. Novati, E. Olivieri, A.S. Zolotarova, H. Cabane, T. Redon, 2020. Experimental and numerical investigations of the Czochralski growth of $\mathrm{Li}_{2} \mathrm{MoO}_{4}$ crystals for heat-scintillation cryogenic bolometers. J. Crystal Growth. 531, 125385. 
[23] J. Castaing, A. Mufioz, D. Gomez Garcia, A. Dominguez Rodriguez, 1997. Basal slip in sapphire (a-Al $\left.{ }_{2} \mathrm{O} 3\right)$, Materials Science and Engineering, A233, pages 121-125.

[24] J.H.P. De Bresser et C.J. Spiers, 1993. Slip Systems in Calcite Single Crystals Deformed at 300-800 ${ }^{\circ} \mathrm{C}$. J. Geophysical Research, 98, B4, pages 6397-6409.

[25] D.A. Spassky, N.S. Kozlova, M.G. Brik, V. Nagirnyi, S. Omelkov, O.A. Buzanov, M. Buryi, V. Laguta, V.N. Shlegel, N.V. Ivannikova, 2017. J. Luminescence. 192 1264-1272.

[26] D.A. Spassky, V. Nagirnyi, A.E Savon, I.A. Kamenskikh, O.P. Barinova, S.V. Kirsanova, V.D. Grigorieva, N.V. Ivannikova, V.N. Shlegel, E. Aleksanyan, A.P. Yelisseyev, A. Belsky, 2015. Low temperature luminescence and charge carrier trapping in a cryogenic scintillator $\mathrm{Li}_{2} \mathrm{MoO}_{4}$. J. Luminescence. 166, 195-202.

[27] M. Velazquez, P. Veber, M. Moutatouia, P. de Marcillac, A. Giuliani, P. Loaiza, D. Denux, R. Decourt, H. El Hafid, M. Laubenstein, S. Marnieros, C. Nones, V. Novati, E. Olivieri, D.V. Poda, A.S. Zolotarova, 2017. Exploratory growth in the $\mathrm{Li}_{2} \mathrm{MoO}_{4}-\mathrm{MoO}_{3}$ system for the next crystal generation of heat-scintillation cryogenic bolometers. Solid State Sciences, 65, 41-51.

[28] A. Ahmine, Croissance Czochralski, comportement et propriétés mécaniques de cristaux massifs de $\mathrm{Li}_{2} \mathrm{MoO}_{4}$ pour bolomètres scintillants, $\mathrm{PhD}$ thesis, $31^{\text {st }}$ Mach 2021, University Grenoble Alpes (in French). 